\title{
Scaffolding Successful Mobile Experiences for Frontline ESL Workers: An Exploratory Study
}

\author{
https://doi.org/10.3991/ijac.v12i3.11182 \\ Anne O 'Bryan ( $\left.{ }^{\varpi}\right)$ \\ University of Massachusetts Boston, Boston, USA \\ Anne. Obryan@umb.edu \\ Lily Compton, Juan David Gutiérrez, Thais Payne \\ University of Massachusetts Boston, Boston, USA
}

\begin{abstract}
This 10-week exploratory study investigates the use of a mobile language learning app, Babbel, by 10 ESL front-line employees and four managers and native English-speaking employees at a Fortune 500 company. We focused on the participants' motivations for using the language learning app and the challenges that they faced. Three key thematic findings were convenience of access, instrumental motivation, and state communicative selfconfidence, while challenges included technological literacy and accountability. Recommendations emphasize the importance of onboarding procedures for those with low technological literacy, continual support from a community of practice, and management participation.
\end{abstract}

Keywords—English as a second language, mobile-assisted language learning, workplace language learning

\section{Introduction}

Mobile-assisted language learning (MALL) applications have the potential to transform the way languages are taught and learned. A remarkable number of people are turning to their mobile devices to learn a second or foreign language. The global market for digital English language learning products, for example, reached $\$ 1.8$ billion in 2013. Revenues were projected to surge to over $\$ 3.1$ billion by 2018 [1]. The language learning app Duolingo had over 70 million sign-ups by 2015 [2]. Babbel, another popular language learning app, sold over one million subscriptions in the United States alone in 2018. MALL opportunities are clearly in demand and will continue to grow in use as more people turn to smartphones or tablets as their primary computing device. Furthermore, the mobile environment enables affordances, both for just-in-time learning as well as learning in small chunks while commuting, for instance, where a learner might have enough time to complete a lesson or review session but not enough time to attend a standard 50-minute course session.

Knowledge of a second language has the potential to improve living standards, access to resources and knowledge, perceived quality of life, and offer more work 
opportunities for adult learners. Here, Ref. [3] identified learners' motivation to learn a foreign language as instrumental motivation with "more functional reasons for learning a language, to get a better job or a promotion" (p.472). Unfortunately, instrumental motivation alone is insufficient for adult learners. When there is limited time available, they must look for more convenient opportunities for language learning than the traditional options of face-to face language classes. MALL applications in the workplace are good alternatives to provide adult learners with convenient and flexible access to language learning resources. Combined with the instrumental motivation, such applications can give adult learners the chance to improve their workplace skills especially if the MALL applications can provide vocabulary and grammar items that closely relate to their workplace interactions.

Independent MALL can be challenging for some language learners because they require a certain level of technological proficiency. With learners who are not technology savvy, they may find it difficult to learn with technologically-mediated learning. Ref. [4] stated that perceived self-efficacy that "is concerned with people's beliefs in their capabilities to produce given attainments" (p. 307) can impact language learners' actions. With MALL, this perceived self-efficacy includes the learners' comfort level with technology. Even if learners were proficient users with social applications on mobile phones, that technological proficiency does not automatically equate to effective MALL since learning through a technologicalmediated environment requires additional skills, such as requiring learners to become familiar with the interfaces that can enable them to communicate with a mobile device in order to be a successful learner.

Additionally, even with extremely motivated learners, it might be difficult to form a new habit over a short period of time. Ref. [5] suggested that the development of a new habit takes an average of 66 days to become an automatic behavior and recommended interventions that aim "to create habits may need to provide continued support to help individuals perform a behavior for long enough for it to be subsequently enacted with a high level of automaticity" (p. 1007). Therefore, learners who do not receive sufficient support during the period of consistent repetition may be unable to establish the level of automaticity that will lead them to be successful independent MALL learners.

Another challenge for independent MALL learners is to transfer their new knowledge into authentic oral interactions. Since the ultimate behavioral goal is for learners to use the second language (L2), the learners must first be willing to engage in oral communication [6]. Willingness to communicate (WTC) is the behavioral intention that is a precursor to the actual behavior of second language (L2) use, while the state communicative self-confidence is one of two situated antecedents that can affect this WTC. Here, Ref. [6] noted that before learners can reach that level of WTC, they must feel "confident enough at that particular moment to communicate effectively" (p.548-549). If this state communicative self-confidence is not achieved, learners may be unwilling to test out their newly acquired knowledge.

Learning more about why employees might want to engage with a language learning app and how employees actually use the app can help us better understand how we might successfully scaffold a mobile language learning experience for 
frontline ESL workers. This paper focuses on the participants' motivations for the use of the language learning app, Babbel, along with the training procedures, support systems, and actual use of the app by employees and managers over a 10-week period.

\section{Methods}

\subsection{Participants}

Fourteen participants were recruited from two separate service-oriented sites in North America. Ten participants were native Spanish speakers and worked as frontline employees at the sites. All Spanish-speaking participants were considered to be at the beginning or low-intermediate level of English language proficiency. An additional four participants were native English speakers; one of these native-English speaking employees held a managerial role at the site. The majority of participants were between 45-64 years of age.

\subsection{Instruments and procedures}

Initial data collection: All ESL participants completed an initial language assessment consisting of 20 vocabulary and grammar questions, as well as two roleplay activities. As the mobile app contains lessons that differ in their level of difficulty, the results of the language evaluation and performance in the role-plays were used to guide ESL participants toward a learning level appropriate to their level of English language proficiency.

Following this, all participants completed a paper-based survey that was designed to both collect demographic information and also measure their language learning motivations, perceived self-efficacy, and perceived quality of life. Using a scale from 1-10 ( 1 being not important and 10 being very important), participants were asked to rate a series of statements that focused on: motivators related to communication in the workplace, daily communication needs, and communication for leisure purposes (e.g., travel), perceived self-efficacy with technology, general learning, language learning, job interactions, and daily interactions, and finally the potential acquisition of second/foreign language for their perceived quality of life based on four areas adapted from Ref. [7]: social, esteem, actualization, and knowledge needs.

The manager participating in the project completed a separate survey that included open-ended questions related to expectations for the project and the benefits of this exploratory study.

Onboarding process: Once initial data collection was complete; the onboarding process included the installation of the Babbel app for learning and tracking purposes. To facilitate communication, this onboarding process was conducted both in English and in Spanish, as needed. Participants were provided with voucher codes for the language learning app. The researchers assisted participants with the mobile app installation on their personal smartphones and the navigation of the learning modules 
on the app. The voucher codes were subsequently used to track weekly participant engagement with learning modules. Participants were given the choice to learn any language that was offered through Babbel. All 10 ESL employees chose to learn English; the remaining four employees chose to learn a variety of languages, including Spanish and Turkish.

The onboarding process concluded with project expectations. Drawing on Ref. [8]'s recommendation, participants were asked to complete one new lesson per day using the Babbel app, spending approximately 15 minutes per day learning with the app, or 105 minutes per week. For three days each week, participants were asked to complete specific modules relating to their workplace context; on other days, participants were encouraged to explore topics of their own interest.

Mid-study data collection: After five weeks, participants again completed the initial survey that focused on language learning motivations, perceived self-efficacy, and perceived quality of life. Finally, participants provided information about their use of the app in open-ended interviews.

Final data collection: At the end of 10 weeks, ESL participants completed the initial language assessment, including the vocabulary and grammar items, as well as the role play, that was administered at the beginning of the study. All participants completed a slightly modified version of the initial survey to, again, capture learners' perceptions of their language learning motivations, perceived self-efficacy, and perceived quality of life. Finally, open-ended interviews were conducted with select participants who met, or exceeded, the recommended time spent with the app per week to ask them about their impressions, challenges, and overall experience with the app.

\subsection{Ongoing communication}

Throughout the 10-week study, researchers remained in close communication with participants. Initially, this happened solely via email. As the project moved along, researchers found that texting was a better way to engage with participants. By the end, a hybrid practice of texting, emailing, and calling had been developed. This communication was an attempt to be proactive about any technological issues that might arise, as well as to help employees establish good practices with the app. Based on usage data received from Babbel's didactics team - which included active days, completed lessons, minutes learnt, and vocabulary reviews - researchers were able to contextualize messages and motivate users according to their individual engagement.

\section{$3 \quad$ Results and Findings}

\subsection{Engagement with the language learning app as a learning tool and convenience of access}

The first thematic finding focused on the engagement with the learning tool and the convenience of access. Results from the data showed that half of the participants were 
able to maintain their engagement by spending at least 50 minutes or more per week learning with the app, while three participants spent more than the recommended 105 minutes per week. These participants reported that the mobility of the app provided them with the opportunities to learn in chunks of time and during their commute and work breaks.

As an example, one employee indicated that it was convenient to use the Babbel app when she arrived at work early in the morning around 4 or 5 a.m. Another employee indicated using her 15-minute break time to study and said that the app was convenient since she could "listen to expressions" and "repeat them and listen to them as many times" as she wanted. An additional employee said that learning English was difficult, but investing her time can pay off, "even if it's five minutes". Other participants also noted that it was convenient to learn during their commute to and from work.

Overall, the mobile app provided affordances for just-in-time learning and convenient access that enabled motivated participants to proceed with their language learning despite busy schedules.

\subsection{Instrumental motivation for language learning}

The second thematic finding focused on participants' instrumental motivation for language learning. Some of the participants stressed the importance of learning the language for both workplace and daily interaction outside of the workplace.

As shown in tables 1 and 2, on average, the ESL participants were more motivated to learn a language than the native-English speakers. Furthermore, data from the initial and final surveys showed that the ESL front-line employees reported consistently high motivation levels to improve their language proficiency for workplace interactions, daily interactions, and for leisure purposes. One employee stated that "learning some words is always useful" so that she would not panic "when someone talks to [her] in English". Another employee indicated that she was motivated to learn with the mobile app because the content included situations that related to their daily interactions, "For example, when you meet someone, when you travel. The vocabulary that you need to use is there, and I liked that a lot; it is very important."

Table 1. ESL front-line employee's average scores for each motivator

\begin{tabular}{|l|c|c|c|}
\hline Motivators & Workplace communication & Daily communication & Leisure/Travel \\
\hline Initial survey & 9.9 & 10 & 10 \\
\hline Exit survey & 9.7 & 10 & 10 \\
\hline
\end{tabular}

Table 2. Native English-speaker employees's average scores for each motivator

\begin{tabular}{|l|c|c|c|}
\hline Motivators & Workplace communication & Daily communication & Leisure/Travel \\
\hline Initial survey & 9.1 & 7.9 & 8.5 \\
\hline Exit survey & 8.8 & 6.9 & 6.8 \\
\hline
\end{tabular}


The differences in motivation are likely due to the nature of the learners and their environments. ESL front-line workers probably have a stronger instrumental motivation to learn the language because they have to rely on the new language to work and live in a new culture. In contrast, native English speakers learning a foreign language may only opt to utilize the foreign language if and when they choose, with little impact on their current work and living conditions. Keeping instrumental motivation in mind, learners are likely to be more engaged if the learning content can mirror the real-life language usage.

\subsection{State communicative self-confidence, perceived self-efficacy, and quality of life}

The third thematic finding focused on increase in state communicative selfconfidence, perceived self-efficacy, and quality of life.

The use of the Babbel app helped to increase the participants' WTC as they experienced higher state communicative self-confidence. Select ESL participants noted that, by the end of this project, they felt more confident and comfortable using English at work. One participant shared that she felt " $a$ bit more confident than before" when communicating with clients. Another participant was able to practice what she had learned when "clients ask basic questions like where the restroom is, etc." She added that she would also "take advantage of [co-workers] who speak English" as opportunities to practice. A manager shared a similar observation as he noticed that "[employees are] not as shy" to use the language.

Additionally, ESL participants who initially indicated low perceived self-efficacy for general technology use reported higher perceived self-efficacy by the end of the study. While most of the participants indicated a high perceived self-efficacy on both the initial and final surveys, four of the ESL participants had rated on the lower end of the scale in the initial survey. However, during the exit survey, these four participants indicated an increase in their perceived self-efficacy for general technology use. One of these four employees indicated a large jump in perceived self-efficacy when it came to using new technology easily and using technology resources to troubleshoot problems (from 1 or 2 to 9 or 10 ).

In terms of perceived self-efficacy with general learning or language learning when provided with relevant resources, all 14 employees indicated a score of 7 or higher. Nonetheless, some of the ESL participants expressed that the weekly email reminders sent by the researchers were extremely helpful for accountability and keeping them on track with their learning goals. In particular, one employee said that the emails kept her "motivated because it [was] a reminder of keep studying and practicing" while realizing that "the goals are for [her] to set" in order to benefit from it. Another employee who didn't have time to log on for a few days when she had guests staying with her felt driven to "take a moment and do some lessons even if just for a couple of days" after seeing an email reminder.

Lastly, employees believed that language learning was important for their quality of life in all four areas: social, esteem, actualization, and knowledge [7]. The results showed the following: 
- Social: 11 employees thought second/foreign language learning was very important to help them interact better with the people they work with. For example, one employee would "take advantage of [co-workers] who speak English as opportunities to practice."

- Esteem: 12 employees learning a second/foreign language indicated the importance of learning the language so that they would gain appreciation and recognition from their supervisors. For example, a site manager noted that the employees "are not as shy" to use the language.

- Actualization: 12 employees perceived learning a second/foreign language as highly important to help them be their best in the workplace. For example, one employee was able to practice what she had learned when "clients ask basic questions like where the restroom is, etc."

- Knowledge: All 14 employees thought that learning a second/foreign language was highly important in their job responsibilities.

Overall, the increase in state communicative self-confidence and perceived selfefficacy, as well as the perceived benefits of language learning for quality of life, contributed to the employees' desire to continue engaging with MALL activities.

\subsection{Importance of training, management participation and continual support for positive outcomes}

Three factors influenced the employees' motivations to use the Babbel app and their continued engagement with the app: the format of the onboarding session used by researchers with the employees, management participation, and ongoing support from the researchers.

Onboarding session: The onboarding session conducted by the researchers to introduce the Babbel app and demonstrate how to use it was more effective when conducted one-on-one with the employees instead of in a small group setting. This initial meeting was also crucial to address all possible questions, establish clear expectations, and troubleshoot technical problems. Additionally, the researchers also stressed the importance of one-on-one sessions to quickly establish a strong rapport with the employees and believed that the common first language (Spanish) facilitated the process and was also beneficial for subsequent positive reception through weekly communication resulting in continuous engagement.

Management participation: Strong support from site managers may have positively impacted employees' use and view of the mobile app. Site managers communicated with both employees and researchers about the various stages of the project. One manager even acted as a role model by using the mobile app to learn a foreign language, clocking in over 60 minutes a week with the app. This level of support and participation was not only helpful for the researchers but also contributed to the development of a positive learning culture.

Ongoing support: Continual support from the researchers in the form of weekly emails and phone texts helped to keep employees motivated and accountable throughout the project. This continued support is integral to helping employees cultivate a 
new habit of language learning with the mobile app as well as making connections between the language learned and the language used in the workplace and in employees' daily lives.

\section{Conclusion}

This exploratory study found that there are affordances provided by MALL for motivated language learners who need flexible and convenient access to instructional materials. Providing such learners with language learning input that closely relates to their workplace needs can improve their state communicative self-confidence that can subsequently increase their WTC. Future studies might consider a short-term structured training program in order to facilitate a stronger community of practice that would enable employees

- Develop necessary skills to use the language learning app effectively to learn a new language

- Cultivate a new habit to support continuous and consistent engagement with mobile learning

- Develop self-efficacy to continue with independent language learning after the completion of this program.

Future studies could focus on the effectiveness of this short-term structured program to provide employees with necessary skills to facilitate their future journeys as independent language learners.

\section{Acknowledgement}

We thank the people at Babbel and Sodexo for their continued support throughout this project. This work was supported in part by Sodexo.

\section{References}

[1] S.S. Adkins. "The US market for mobile learning products and services: 2008-2013 forecast and analysis". Ambient Insight, 5, 2008.

[2] S. Hickey. "Learning the Duolingo - how one app speaks volumes for language learning". The Guardian News and Media Limited, 2015. Retrieved from https://www.theguardian.com/business/2015/mar/08/learning-the-duolingo-how-one-appspeaks-volumes-for-language-learning

[3] R.C. Gardner. Social psychological aspects of second language acquisition. Department of Psychology, University of Western Ontario, 1978.

[4] A. Bandura (2006). "Guide for constructing self-efficacy scales.” In F. Pajeras (Ed.) SelfEfficacy Beliefs of Adolescents, Information Age Publishing, pp. 307-337.

[5] P. Lally, C. H. van Jaarsveld, H. W. Potts, and J. Wardle. "How are habits formed: Modelling habit formation in the real world", European Journal of Social Psychology, vol. 40, 2010, pp. 998-1009. https://doi.org/10.1002/ejsp.674 
[6] P. D. MacIntyre, Z. Dörnyei, R. Clément, and K. A. Noels. "Conceptualizing willingness to communicate in a L2: A situational model of L2 confidence and affiliation." The Modern Language Journal vol. 82, no. 4, 1998, pp. 545-562. https://doi.org/10.1 111/j.1540-4781.1998.tb05543.x

[7] M. Sirgy, J. D. Efraty, P. Siegel, and D. Lee. "A new measure of quality of work life (QWL) based on need satisfaction and spillover theories." Social indicators research vol. 55, no. 3, 2001, pp. 41-302. https://doi.org/10.1023/A:1010986923468

[8] C. Larkin. "How To Learn A Language In 20 Minutes Per Day". 2018. Retrieved from https://www.babbel.com/en/magazine/learn-language-20-minutes/

\section{$7 \quad$ Authors}

Anne O'Bryan is a lecturer in Applied Linguistics at the University of Massachusetts Boston. Her primary research areas are in online language teaching and learning, teacher education, and computer-assisted language learning.

Lily Compton is a lecturer in Applied Linguistics at the University of Massachusetts Boston. Her primary research areas are in computer-assisted language learning, online language teaching and learning, teacher education, and curriculum and instructional technology.

Juan David Gutiérrez is a third-year Ph.D. student in Applied Linguistics at the University of Massachusetts Boston. His research interests include language identity, language teaching and learning, language policy, and curriculum.

Thais Payne is a second-year master's student of Applied Linguistics at the University of Massachusetts Boston. She is a 6-12 English as a Second Language teacher and aspiring Ph.D. candidate.

This article is a revised version of a paper presented at the International Conference on E-Learning in the Workplace 2019 (ICELW 2019), held in June 2019, at Columbia University in New York, NY, USA. Article submitted 2019-07-03. Resubmitted 2019-08-05. Final acceptance 2019-08-07. Final version published as submitted by the authors. 